\title{
Práticas e eventos de letramento em meios populares: uma análise das redes sociais de crianças de uma comunidade da periferia da cidade do Recife
}

\author{
Ana Cláudia Ribeiro Tavares \\ Andréa Tereza Brito Ferreira \\ Universidade Federal de Pernambuco, Programa de Pós-Graduação em Educação
}

\section{Introdução}

Comunidades de baixo poder aquisitivo e/ou de risco social são consideradas "meios iletrados" por apresentarem baixos níveis de rendimento escolar ou de competências de leitura e escrita. Nesse sentido, as crianças provenientes desses ambientes são comumente associadas, nos diagnósticos e documentos norteadores das políticas públicas de educação, à ideia de fracasso escolar. O argumento não é novo. Nos anos de 1980, estudos e pesquisas que analisaram o fenômeno do fracasso escolar (Dorneles, 1987; Soares, 1986), após superarem as abordagens psicopedagógicas que explicavam o fenômeno através da existência de diferenças individuais na capacidade de aprendizagem, fizeram das "diferenças culturais" a premissa explicativa para o fracasso das crianças oriundas dos meios populares.

Para as primeiras explicações, aquelas provindas da abordagem da "ideologia do dom", a existência do fracasso escolar nos meios populares provinha das desigualdades naturais, ou seja, a não-aprendizagem se daria pelas desigualdades e diferenças nas aptidões intelectuais de cada aluno. Em relação à aprendizagem da leitura e escrita, trabalhava-se objetivando a decodificação de um código linguístico.

Embora ainda se presenciem resquícios dessa abordagem em alguns discursos e instituições educacionais, a ideologia das diferenças individuais foi superada, ao longo do tempo, por novos estudos que apontavam serem as diferenças não apenas entre indivíduos, mas entre as classes culturais e sociais a que eles pertencem (Bourdieu \& Passeron, 1975). Este último pressuposto levou a um movimento de expansão ao acesso dos meios populares à escola, que conviveu com as orientações seletivas tradicionais dos sistemas de ensino e trouxe em seu bojo uma nova figura: “os excluídos de dentro” (Sposito, 2007; Bourdieu, 1998). Para esse tipo de compreensão, defende-se a ideia de "carência cultural”, ou seja, acredita-se que as crianças das classes populares são "produto de um ambiente cultural desfavorecido, pobre em estímulos e vivências, que não favorece seu desenvolvimento" (Dorneles, 1987, p. 257).

Por essa via, constituiu-se nas ciências humanas e sociais uma visão de negatividade em torno dos 
valores e práticas das famílias das classes populares como “espelho" da própria "moral dos pobres” (Sarti, 2003). Como resultado, enfatiza-se uma "cultura da pobreza" como critério definidor das demandas e dos resultados escolares.

Não obstante, estudos sociológicos recentes (Lahire, 2005; Rodrigues \& Bosco, 2005; Wacquant, 2001; Lewis, 1999) têm-se debruçado sobre situações consideradas atípicas: famílias que acumulam "deficiências" de leitura e escrita e que não dispõem “objetivamente" de seus atributos e recursos e apresentam crianças com "sucesso escolar” e, por outro lado, famílias não totalmente "desprovidas de recursos", sobretudo do ponto de vista do capital cultural, mas que apresentam crianças com enormes dificuldades escolares. Essas pesquisas contribuem para uma análise crítica dos dados estatísticos das avaliações sobre o uso da leitura e escrita, por não revelarem adequadamente as condições nas quais esses dados são produzidos e como são produzidos, além de, muitas vezes, aproximarem numa mesma categoria realidades consideradas diferentes.

Acreditamos que a discussão das práticas de letramento só faz sentido se essas práticas forem abordadas a partir de condições que tornem possível sua compreensão contextual, e não como mais um "modismo educativo". O debate em torno das práticas e dos eventos de letramento visa a problematizar as disposições culturais susceptíveis de ajudar as crianças na aprendizagem das práticas de leitura e escrita e, mais amplamente, de socializá-las junto às redes sociais mediante processos de ampliação e reconhecimento de seus direitos de cidadania. Assim, nossa pesquisa apresenta duas categorias-chave como construtos teóricos fundamentais sobre as práticas de escrita: "letramento" - indicando algo mais que a apropriação da tecnologia da escrita (alfabetização) e, para não fazermos de conta que a compreensão de casos singulares acontecem por si sós, optamos pela escritura sociológica das "redes sociais".

A problematização que moveu este trabalho de pesquisa questionou: por que algumas crianças apresentam boas competências de leitura e escrita enquanto outras que habitam a mesma comunidade concluem as primeiras séries do ensino fundamental ainda analfabetas? Como essas práticas se inter-relacionam no cotidiano da comunidade e quais seus impactos no processo de socialização das crianças dos meios populares, principalmente quando se consideram as demandas geradas para sua inserção em um mundo crescentemente letrado?

Nossa hipótese sugeria que a transmissão da língua e a significação que as crianças conferem aos momentos de leitura e escrita ocorrem ao longo de redes sociais delimitadas (espacial e temporalmente) pelas práticas de letramento, que são sempre práticas de intercâmbio de algo. Esse "algo" pode ser: atividades conjuntas, conversas informais, o empréstimo de um objeto cultural (livro, revista, música, software); "algo" que adquire, assim, valor simbólico.

Acreditamos que este trabalho de pesquisa sobre letramento e redes sociais, desenvolvido no âmbito do mestrado de educação, pode contribuir para explicitar novos referenciais teórico-metodológicos que possibilitem avançar no debate e nas práticas de formação dos sujeitos, materializando assim o papel da universidade pública na promoção de estudos e desenvolvimento de saberes que atuem diretamente no exercício dos direitos de cidadania arduamente conquistados pela sociedade brasileira.

O objetivo geral desta pesquisa é investigar as práticas e eventos de letramento em uma comunidade da periferia da cidade do Recife, a partir dos momentos de interação das crianças com a escrita, pela ótica de suas redes sociais de pertencimento. Para atingi-lo, é necessário ser bem-sucedido em dois objetivos específicos: identificar a presença das práticas de letramento nas redes de pertencimento significativas das crianças; e verificar os eventos de letramento nos espaços que compreendem o mapa de redes sociais de pertencimento das crianças na comunidade.

\section{Letramento: constituição e desenvolvimento nas práticas sociais}

Embora já houvesse estudos sobre o letramento entre as décadas de 1970 e 1980, foi a partir desta últi- 
ma que surgiram novas abordagens sobre o fenômeno, convergindo ideias de pesquisadores e estudiosos interessados em apresentar novas linhas de pensamento sobre esse campo de estudo.

Nesse cenário de discussões, uma das primeiras posturas teóricas a ser questionada é a que aborda o letramento como tecnologia da escrita que, em si mesma, desenvolveria as habilidades cognitivas dos sujeitos. A escrita é avaliada como um sistema de representação gráfica detentor de qualidades intrínsecas, capaz de, por si só, promover o desenvolvimento social e cultural dos povos e dotar aqueles que dela se apropriam de habilidades cognitivas - como a habilidade de decodificar as letras - que os levariam, mais a frente, ao aperfeiçoamento do pensamento abstrato e da racionalidade (Lopes, 2006). Street (1984) considera essa compreensão um modelo “autônomo de letramento".

Outra vertente teórica traz em seu discurso o letramento como um conjunto de práticas socioculturais situadas em determinado contexto. Essa concepção aborda a linha de investigação denominada "Novos estudos do letramento" ou "Estudo sobre letramentos sociais”. Em um sentido mais amplo, essa perspectiva compreende que a linguagem, enquanto forma de interação social, não se limita apenas às suas propriedades formais e qualidades intrínsecas, mas sobretudo em função da legitimação de usos reais pelos indivíduos. Além de propor uma nova forma de investigação da escrita, Street (1984) identifica um segundo modo de confirmar o letramento, o qual denomina "modelo ideológico” de letramento.

Esse "modelo ideológico" traz uma perspectiva de maior sensibilidade cultural das práticas de letramento a partir do momento em que elas variam de um contexto para outro. Esse modelo parte de premissas diferentes das adotadas pelo modelo autônomo ao propor o letramento como uma prática de cunho social e não meramente uma habilidade técnica e neutra, que aparece sempre envolta em princípios epistemológicos socialmente construídos.

$\mathrm{O}$ argumento sobre os letramentos sociais sugere que o engajamento no letramento é sempre um ato social, desde o seu início. As formas como interagem professores ou facilitadores e seus alunos é sempre uma prática social que afeta a natureza do letramento a ser aprendido e as ideias que os participantes possam ter sobre o processo, em especial os novos aprendizes e sua posição nas relações de poder. A capacidade de enxergar além dos limites do código, de fazer relações com informações fora do texto falado ou escrito e vinculá-las à sua realidade histórica, social e política é característica de um indivíduo "plenamente letrado".

\section{O conceito de letramento}

A palavra "letramento" é um termo recente nos estudos acadêmicos no Brasil, especificamente nas áreas de educação e linguística. É a tradução para a língua portuguesa, de forma literal, da palavra inglesa literacy. Enquanto não constatamos seu registro no inventário léxico dos dicionários brasileiros, na língua inglesa, encontramos o termo já dicionarizado desde o século XIX e, "na segunda metade do século $\mathrm{XX}$, tornou-se frequente e indispensável na literatura especializada, notadamente nas áreas de educação e das ciências sociais" (Lopes, 2006, p. 39).

Seu surgimento em estudos e pesquisas nas áreas acadêmicas, no Brasil é datado da década de 1980, e atualmente se insere em outros espaços da sociedade, sendo-lhe atribuídos, por isso, diferentes significados e objetivos. Pode-se, então, dizer que conceitos, definição e significação do termo letramento são conhecimentos que se encontram em construção (Mortatti, 2004). Nesse sentido, o surgimento do termo letramento deu-se quando emergiram novos contextos, novas ideias, novos fatos, novas maneiras de compreender os fenômenos sobre a leitura e a escrita.

A ideia de letramento visa relacionar as mediações ocorridas entre os sujeitos e suas relações sociais e o mundo da cultura escrita. Por essa via, o indivíduo letrado é "aquele que vive em estado de letramento, e não só aquele que sabe ler e escrever, mas o que usa socialmente a leitura e a escrita, pratica a leitura e a escrita, responde adequadamente às demandas sociais de leitura e de escrita" (Soares, 1998, p. 40). 
Isso implica afirmarmos que o modo como a linguagem circula nos diferentes contextos depende da variabilidade e dos significados que surgem, diante da articulação dos usos da leitura e escrita, ligados aos vários sujeitos em interação. Cotidianamente o indivíduo faz uso das práticas de leitura e escrita, que são decorrentes de sociedades letradas, desde sua casa (rótulos de embalagens, propagandas televisivas etc.) até seu contato com as várias faces de uma cidade (slogans de lojas, propagandas em outdoors, marcas de roupas, propagandas de lanchonetes, linhas de ônibus). Essas práticas acontecem dentro de um contexto próprio às situações sociais.

\section{Pressupostos metodológicos e a contribuição da análise das redes sociais às práticas de letramento: um estudo de caso na comunidade do Coque}

Para que se possa melhor compreender as práticas de leitura e escrita enquanto tecnologia e sistema simbólico, é importante ressaltar que, para as ciências sociais, o paradigma das redes sociais, de um lado, é concebido como uma teoria substantiva, definindo uma realidade específica. Por outro, o termo assume conotações instrumentais, sendo abordado como uma metodologia de análise e um instrumento para a organização de dados científicos (Freitas, 2005).

Do ponto de vista teórico, o conceito de rede social designa um conjunto de pessoas ligadas por relações sociais mais ou menos habituais e conectado com outras redes por linhas mais ou menos fortes de relação. Cada pessoa faz parte de múltiplas redes sociais interligadas (Cáccamo, 2004). A linguagem, enquanto força cultural, atua na complexidade dessa rede construindo laços e dando modalidades de relação nos âmbitos mais variados. De acordo com esses espaços, as redes sociais se classificam em redes sociais primárias e redes sociais secundárias.

As redes sociais primárias constituem os "nós" que integram as relações mais estreitas, sendo os contatos pessoais mais diretos e com maior grau de compromisso entre os sujeitos. As redes sociais secun- dárias são formadas por profissionais e funcionários de instituições públicas ou privadas; organizações pessoais, organizações não-governamentais, grupos organizados de mulheres, associações comunitárias e religiosas.

Como abordagem metodológica, a análise de redes não constitui um fim em si mesma. Ela é o meio para realizar análises cujo objetivo é mostrar de que maneira a rede é explicativa dos fenômenos analisados.

Tomamos como sujeitos diretos de investigação de nossa pesquisa duas crianças participantes da instituição que já tivessem se apropriado do sistema de escrita alfabética. A decisão de desenvolver uma análise tendo como foco crianças já alfabetizadas foi motivada, além do fato da exposição às práticas sociais que eram intermediadas pela palavra escrita, pela percepção de um uso efetivo da escrita, pois, nesse sentido, sua utilização requer, em princípio, um certo domínio do sistema de escrita alfabética pelos seus usuários.

Durante nossa aproximação com a comunidade, realizamos várias visitas a uma instituição não-governamental. Uma das ações desenvolvidas pela instituição contemplava as crianças na faixa etária de 7 a 9 anos que frequentavam regularmente a escola.

Buscamos identificar, em um primeiro momento, o contexto social, político e cultural das crianças que participaram de nossa pesquisa, pois é nele também que as práticas e os eventos de letramento investigadas estavam inseridos. Por essa razão, adotamos um instrumento denominado "mapa de redes” (Sluzki, 1997). Esse instrumento possibilitou, ao investigar as redes pessoais das crianças, o reconhecimento da "teia social”, bem como suas experiências com a leitura e a escrita no seu cotidiano.

Em cada quadrante inscrevem-se três áreas: um círculo interno, de relações íntimas, diretas, cotidianas e de maior grau de compromisso, constituindo as redes primárias; um círculo intermediário, de relações sociais de contato pessoal sem intimidade; e um círculo externo, de relações ocasionais.

O uso desse dispositivo forneceu a chave analítica para entender as práticas de letramento na comunidade investigada, uma vez que possibilitou a representação 
dos números relativos de vínculos que cada informante teria na comunidade. Nesse contexto, a "dinâmica” dos usos da leitura e escrita constou da investigação das seguintes unidades: práticas e eventos de letramento, a partir dos espaços, instituições e vínculos circunscritos no mapa de redes de cada criança e como categorias de análise, foram o modo de circulação do letramento nos espaços circunscritos no mapa.

Figura 1: Mapa de rede

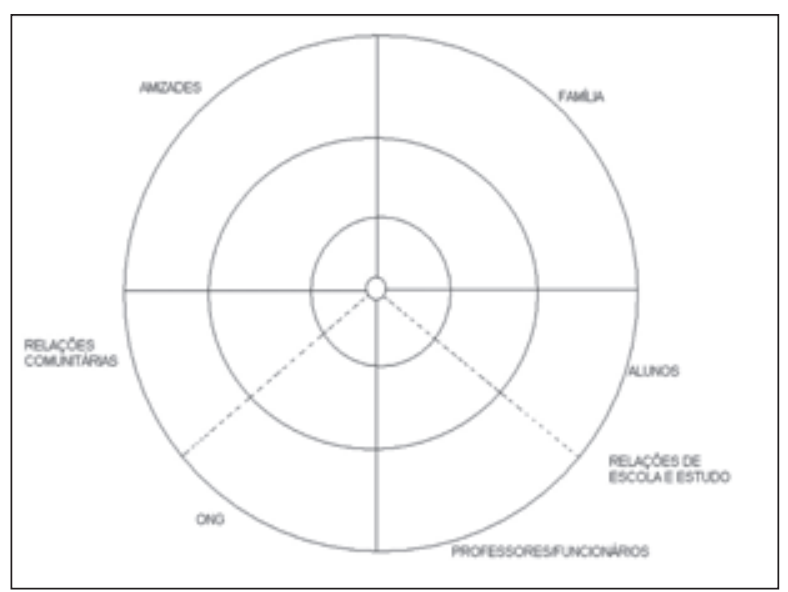

Fonte: Sluzki (1997).

Uma vez delineadas as micro e macrorredes de pertencimento social dos sujeitos da pesquisa após a aplicação dos mapas, realizamos entrevistas com as crianças e os sujeitos indicados por elas para construirmos dados mais qualitativos sobre como acontecem as relações/interações com as múltiplas práticas e eventos de letramento.

Concomitantemente, fizemos observações, para investigar usos e significados na comunidade escolhida (Geertz, 1978) no período de dois meses, com ressalva para o fato de que qualquer generalização que se possa fazer nesse tipo de interpretação se deve muito mais à delicadeza das descrições do que à amplidão das abstrações.

\section{Resultados: concepções e práticas reveladas nas cenas de letramento}

É na necessidade de relações com os outros e com os bens simbólicos que surgem as redes sociais, de forma que estamos imersos em uma trama ou rede progressivamente complexa de interdependências (Chadi, 2000).

Para abordar as práticas de letramento que as crianças nomeiam e reconhecem em suas redes sociais, especificamente as primárias, preocupamonos em entender os laços no sentido de intercâmbio das práticas e eventos nos espaços delimitados em seus mapas.

Embora as configurações das crianças sejam singulares, e por consequência as escritas sobre elas também, os textos produzidos não são isolados entre si, pois, de um lado, trabalhamos com as mesmas orientações interpretativas, e, de outro, na ótica das redes sociais o texto de cada perfil se conecta ao texto de todos os outros perfis. O mais particular ou singular de cada indivíduo será entendido se reconstituirmos o tecido de imbricações sociais com os outros.

Nossos estudos consistiram em, mais do que relevar ou privilegiar um ou outro aspecto das configurações mapeadas nas redes sociais das crianças, descrever e analisar as relações específicas de aspectos gerais no âmbito das redes sociais. No entanto, para este artigo, optamos por apresentar as relações entre as práticas de letramento das redes sociais primárias (família) e as redes sociais secundárias (escola).

\section{Configurações de pertencimento - Joyce}

Figura 2: Mapa de rede - Joyce

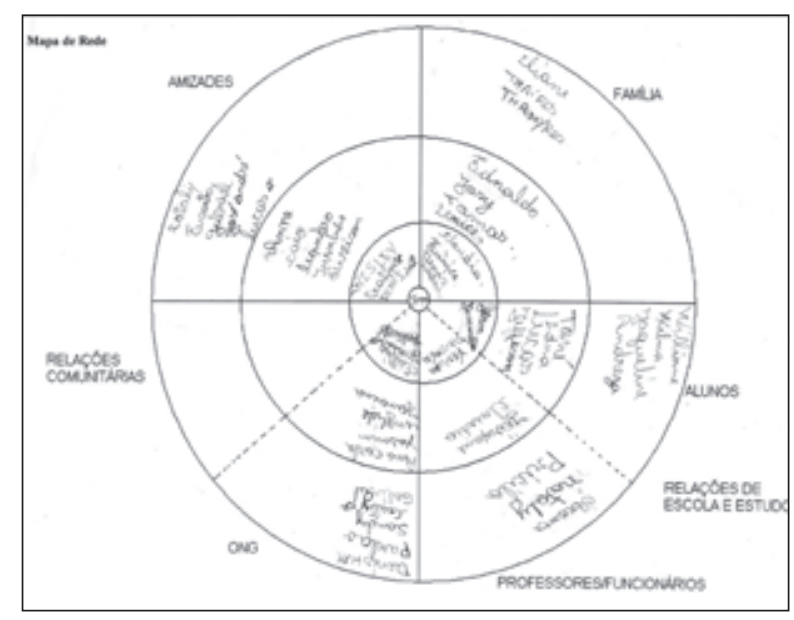




\section{Configurações de pertencimento - Lucas}

Figura 3: Mapa de rede - Lucas

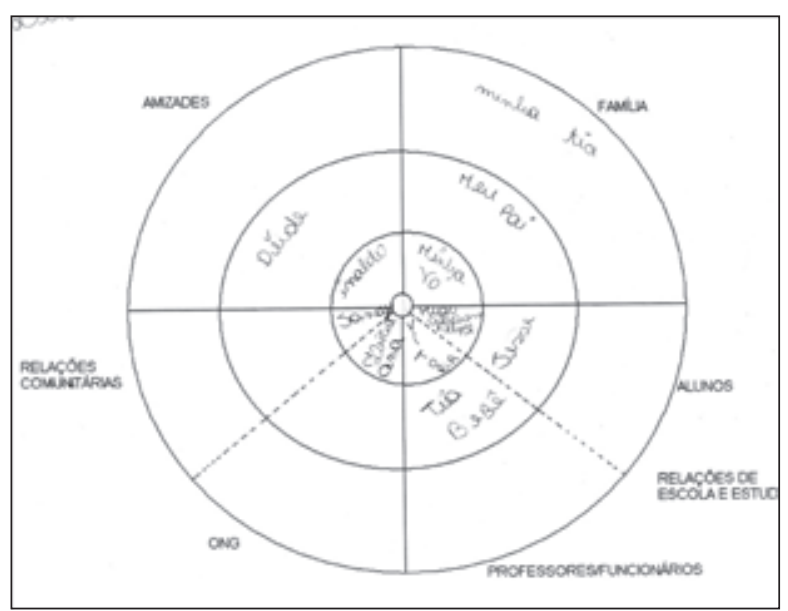

Família

Joyce tem nove anos, estuda em uma escola da rede pública do município de Recife, está cursando o $2^{\circ}$ ano do $2^{\circ}$ ciclo e alcançando bom desempenho na escola. Mora com o irmão mais velho (13 anos) e sua mãe. Há cinco anos seu pai saiu de casa; embora ainda more na comunidade, ela o vê raramente. Atualmente ele trabalha em uma empresa de terceirização de serviços gerais e auxilia apenas nas despesas alimentares. Ele e a mãe de Joyce, dona de casa, cursaram apenas as séries iniciais do ensino fundamental, completando quatro anos de escolarização. Dominam com dificuldade o sistema de escrita alfabética, embora sua mãe faça uso mais amplo das práticas de leitura e se mostra participante na vida escolar da filha, mesmo antes de ela ter acesso ao sistema formal de ensino.

\footnotetext{
Antes dela ir para o colégio, eu já ensinava ela a ler e escrever, ensinava o que eu sabia. Quando ela foi pro colégio, já foi sabendo. Os dois, da primeira série, passaram, logo no meio do ano, para a segunda, depois fizeram a terceira, e assim foi... Não repetiram nenhum ano, não [...] Pra ser alguém na vida, pra ter um bom emprego, tem que ter estudo. Tem que ler as coisas bem. (Eunice - mãe de Joyce)
}

Percebemos, atrelado ao discurso da mãe de Joyce, o reconhecimento de questões consideradas por ela importantes sobre o que o conhecimento, a leitura e a escrita podem possibilitar a seus filhos. Young (2007) diz que, principalmente em países em desenvolvimento, é isso que a maioria dos pais esperam, mesmo que inconscientemente, ao fazer sacrifícios para manter seus filhos na escola.

Das relações familiares, Joyce aponta sua mãe, seu irmão e seu tio Valdmir como as pessoas que estão lendo e escrevendo (com exceção de sua tia Cláudia, todos se encontram no círculo de maior proximidade em seu mapa de redes sociais). Sobre sua mãe, Joyce comentou que ela gosta de ler os textos do livro didático de português, enquanto seu irmão lê geralmente gibis (que pega emprestado na biblioteca da instituição de que participa - Turma da Mônica e livro de samurai). Seu tio também gosta de ler gibis e, quando estudava (parou este ano, devido ao trabalho na oficina), fazia as tarefas em casa.

Sobre os outros familiares, Joyce afirmou que suas tias gostam de ler revistas e a seção do jornal que comenta as novelas. Para ela, seu primo Tomás não faz uso de materiais escritos, pois "ele não sabe ler nem escrever”. A ênfase na compreensão de que é preciso aprender a ler e escrever, enquanto processo de codificação e decodificação, para só efetivamente poder compreender o que se veicula nos textos escritos, recai não apenas na concepção das crianças como também pelos adultos que constituem suas redes sociais primárias.

Lucas tem 10 anos e cursa o $2^{\circ}$ ano do $2^{\circ}$ ciclo. Mora com a avó, a mãe, uma tia e um tio. Com exceção de sua avó, todos estão empregados e passam o dia fora de casa. Como ele mesmo aponta em seu mapa de redes, no âmbito familiar, tem um vínculo intenso com sua avó. Está reservada a ela a educação escolar de Lucas.

Percebemos que as duas crianças não reproduzem, necessariamente e de forma direta, as formas de agir dos adultos nos eventos de letramento que ocorrem na família; entretanto, encontram suas próprias modalidades de comportamento em relação à leitura e a escrita, de acordo com as relações de interdependência no âmbito das quais estão inseridas. Nesse sentido, percebemos que, para o envolvimento das crianças em 
práticas de letramento, é necessário, além do sentimento de serem capazes de ler, de compreender de forma autônoma o texto que têm em mãos, que contem com as ações dos adultos ou "outros" mais experientes. Estes, mesmo sem saber, atuam como apoios relacionais em que as crianças desenham e se permitem espaços de comportamentos e representações possíveis para elas. Deve-se ressaltar, assim, que as práticas de letramento realizadas pelas crianças não acontecem em um vazio de relações sociais, mas que é através dessas relações que as próprias práticas de letramento nos meios populares são atualizadas e mobilizadas.

Entre os materiais escritos que circulam no âmbito das redes sociais primárias, verificamos a presença dos seguintes:

\begin{tabular}{|c|l|}
\hline Crianças & \multicolumn{1}{|c|}{ Matérias de leitura e escrita } \\
\hline Joyce & $\begin{array}{l}\text { Livros didáticos, revista, caderno, jornal, } \\
\text { livros de histórias, gibis, diários, livros } \\
\text { literários de tradições religiosas. }\end{array}$ \\
\hline Lucas & $\begin{array}{l}\text { Livros de literatura infantil, cartas, contas } \\
\text { de água e luz, textos do curso (português } \\
\text { e filosofia). }\end{array}$ \\
\hline
\end{tabular}

No caso de Joyce, é interessante perceber que a possibilidade de acesso aos materiais de leitura e escrita acontece na circulação deles entre os familiares.

Nesse sentido, as práticas familiares investigadas na comunidade com textos escritos não têm apenas um papel de exemplo dado às crianças; apresentam-se também para elas através da organização doméstica com práticas que as tornam possíveis e as quais possuem um efeito indireto, no entanto, "poderoso".

Eu sempre li os livros da escola pra eles. Eu ensino a eles. Algumas coisas que eu sei, eu ensino. Agora, que tiraram a tarefa de casa... Não sei por quê, mas as professoras dizem que é melhor fazer lá do que em casa. Porque, quando manda para casa, elas dizem que eles não fazem, elas fazem lá mesmo a tarefa. Mas eu incentivo eles a estudar em casa, eu mando eles pegarem o livro da escola pra ficar lendo, às vezes eu fico lendo com eles. É importante aprender as coisas da escola. (Eunice - mãe de Joyce)
Embora o uso desses materiais aconteça nas relações familiares, em geral são adquiridos na ação de troca com outros espaços, muitos a título de empréstimo, seja na biblioteca da comunidade ou na escola, seja em outras instituições e, ainda, de colegas próximos.

Ainda nos referindo às práticas de leitura e escrita nas redes primárias, os escritos domésticos vão além de seu papel cultural imediato para se localizar como mediadores de uma organização doméstica. Esses materiais de escrita doméstica, enquanto técnicas comuns de gestão do cotidiano que implicam uma relação com a linguagem e, quase sempre, uma relação com a ordem, participam de formas de organização mais racionais, nas quais a criança está sendo continuamente socializada (Lahire, 2005).

\footnotetext{
É que minha vó, ela não saber ler, aí tem algumas coisas que ela pede para eu ler, que ela ganha alguma carta, ela quer deixar recado para alguém, assim. Qualquer coisa, por exemplo, a conta de luz, ela não sabe os números, ela pede para eu ver quanto é que tem. (Lucas)
}

Com isso, verificamos que a ausência de uma ação voluntária de compartilhamento das práticas de leitura e escrita entre os familiares não impossibilita a criança de se apropriar do seu uso, principalmente nos conhecimentos escolares.

\section{Escola}

No âmbito das redes sociais, a escola é percebida como uma instituição híbrida, que possibilita às crianças compartilhar outros espaços educativos de socialização secundária, ou seja, a escola é geralmente a primeira instituição que se inclui na vida familiar e possibilita que os alunos "atravessem as fronteiras" de novas relações sociais (Dabas, 2003).

Compreendemos que a escola se constitui em âmbito imprescindível para as práticas de leitura e escrita; por isso é preciso que esteja incorporada ao quadro de maior complexidade das relações entre as agências socializadoras em que as crianças fazem uso das práticas de letramento. 
A “tensão” gerada no contexto de ensino-aprendizagem da rede escolar que atende a comunidade do Coque aparece sob a forma de contradição: percebemos, de um lado, que a educação, tal como hoje a entendemos, continua sendo concebida como um instrumento para a conquista da liberdade e da autonomia do sujeito (Sacristán, 2000), ao mesmo tempo em que possibilita a esse sujeito o estabelecimento de laços sociais dentro dessa instituição social. Esse pressuposto é expíicito no depoimento que segue:

\begin{abstract}
Andréa não é a minha professora, ela não ensina a turma, mas acho ela uma boa professora pelo que eu vejo e os meninos fala. Eu sempre vejo ela com livros no braço e também quando ela vai para a faculdade. Eu vejo ela saindo. [...] Já Tia Vanuza foi minha professora em outra série. Ela levava os meninos que queriam estudar e fazer tarefa para a casa dela [ela morava próxima à comunidade] e lá deixava a gente fazer trabalho no computador. A casa dela é feito uma biblioteca, tem estantes com livros que ela deixa a gente pegar. Tem até livros de inglês. [...] Jeisyane foi minha professora na segunda série, e também converso muito com ela e estudo, ela me ajuda nas pesquisas e tarefas do curso e da escola. [...] Cláudia é minha professora, mas eu tenho pouco contato, não chego muito perto não. (Joyce)
\end{abstract}

Por essa via, compreende-se que, ao longo de tempo, a escola universalizou-se não apenas como uma prática social instituída, mas também como uma representação coletiva, condensando um conglomerado de significados, valores e expectativas que retroagem sobre a própria imagem que a sociedade tem de si mesma (Freitas, 2005).

As práticas de leitura e escrita reflexivamente dirigidas fazem-se a partir de determinados modelos ideais, seja na família, na escola ou nas relações comunitárias. Quando se fazem no âmbito escolar, constituem laços e amparam modalidades especificas de relação, tanto as que são dirigidas reflexivamente quanto as que são espontâneas.

\footnotetext{
A professora, lá na escola, ela não faz nada. Passa as coisas que a gente já sabe. Na escola, toda vez eu... Vê por que lá marca, né? Por exemplo, quem fizesse as tarefas pintava
}

de verde, quem não fizesse pintava de azul. Aí eu tinha não sei quantas de azul, que eu nunca fazia as tarefas que ela mandava. Mas eu gosto de ler, de fazer as tarefas do livro. [...] A professora gosta de mim, quer dizer, assim... Porque eu puxo no pé dela: olha, tia, eu faço isso: ó, tia, como é que tá? Ela gosta de mim. Ela manda a gente ir pra frente, se a gente errar alguma coisa ela reprova a gente, mas é para fazer medo à gente. (Lucas)

O contexto escolar constitui um dos diversos espaços de constituição da subjetividade individual dos alunos, assim como de expressão da subjetividade social (Martínez, 2004). Para os alunos, a sala de aula tem, nesse processo de constituição, um importante papel pelas reflexões e vivências emocionais que produzem neles e pelo significado e valor que atribuem às ações pessoais, influenciando os sujeitos de formas diversas.

Dos materiais de escrita que permeavam o cotidiano escolar, encontramos:

\begin{tabular}{|c|l|}
\hline Crianças & \multicolumn{1}{|c|}{ Materiais de leitura e escrita } \\
\hline Joyce & $\begin{array}{l}\text { Dicionários, resumos de livros, livros } \\
\text { didáticos, cadernos. }\end{array}$ \\
\hline Lucas & Textos dos livros didáticos, caderno. \\
\hline
\end{tabular}

Além da fala e da escuta, a sala de aula compreende momentos de interação com a leitura e a escrita, ou melhor, a escola é um espaço de cultura escrita. No entanto, embora institucionalmente a escola possibilite o acesso ao conhecimento especializado, incluído em diferentes domínios, e os diferencie entre conhecimento escolar e o cotidiano (Young, 2007), por detrás dessas categorias socioprofissionais da escola permeiam-se intrinsecamente diferentes níveis de recursos a práticas de leitura e escrita, diferentes modalidades de uso da leitura e escrita, diferentes modos de representação dos eventos de letramento e, por fim, diferentes sociabilidades em torno do texto escrito. Lahire (2005) acrescenta que as práticas escritas podem possibilitar a distância entre o sujeito falante e sua linguagem e lhe dão os meios de dominar de forma simbólica o que então domina de forma prática: a linguagem, o espaço e o tempo. Provavelmente, ainda que de modo implícito, é isso que as mães esperam de seus filhos 
ao buscar mantê-los por mais tempo em instituições educacionais (formais e não-formais).

Eu acho é que eles devem estudar mesmo, aprender na escola o que a gente não sabe ensinar em casa. A gente ajuda em casa, mas eles têm que aprender lá. Assim, como é que eles vão pra faculdade? Por isso, além da escola, ele frequenta o projeto. (Avó de Lucas)

\section{As relações entre as práticas e eventos de letramento nas redes sociais das crianças}

Os membros mais alfabetizados da casa eram as crianças, em geral com grau de escolarização maior que o dos pais. Como analisamos, constatamos, no conjunto das redes sociais, que "os outros significativos" nos eventos de leitura das crianças correspondiam não apenas aos sujeitos adultos, mas também a outras crianças.

Embora as crianças apontem que circulam por vários espaços na comunidade e fora dela (escolinhas de reforço, biblioteca), são os eventos de letramento no contexto familiar, permeados pelo uso do livro didático e da literatura infantil, que as crianças legitimam como práticas de leitura e escrita.

Todos os sujeitos mencionados como referência de leitores e/ou escritores são citados no mapeamento das redes sociais. Outra questão é que a maioria das pessoas indicadas como leitoras estão no quadrante da família e ocupam o primeiro ou segundo círculo.

Nessa perspectiva, os vínculos sociais são significativos para o desenvolvimento ao se converterem em fonte de produção de sentido; uma dialética particular entre o individual e o social é esboçada, evitando considerar o individual e o social categorias dicotômicas e excludentes (Martínez, 2004).

Outro ponto refere-se ao fato de encontrarmos materiais de leitura em todas as redes primárias das crianças. As variações aconteceram em relação aos suportes textuais (livros, jornais, revistas). Na maioria delas, a leitura é apreendida de maneira similar à escola, como é o caso (já citado) da leitura de livros didáticos em casa.

Como pudemos constatar, raramente as práticas de leitura eram realizadas solitariamente. $\mathrm{O}$ fato de serem feitas em voz alta parecia constituir um fator decisivo para que as leituras contribuíssem efetivamente para a inserção das pessoas, mediadas por um membro do grupo que possuía maior intimidade com a escrita, com o mundo letrado.

Consideramos que, nas práticas de letramento das redes sociais das crianças participantes e no contexto escolar, o “outro social” (pai, mãe, avó, irmão, professora) não ocupa apenas um lugar de comunicar mensagens que levam à construção de identidades individuais, mas sim que acontece um complexo processo de troca e participação ativa que gera e integra os processos de desenvolvimento que estão presentes na “constituição subjetiva” de cada um dos atores sociais.

Nas relações entre escola e família, ressaltamos a posição que as redes primárias das crianças apresentam: os meios populares dão grande importância a uma determinada ordem moral - "o bom comportamento" - e respeito à autoridade, não apenas do professor, mas também daqueles que gerenciam a escola, pois, devido a seus baixos níveis de escolarização, acreditam não conseguir ajudar os filhos nas atividades escolares como deviam e então solicitam que se comportem corretamente, que aceitem fazer o que lhes é pedido, que evitem brincadeiras em sala de aula, prestem atenção e estudem. Desse modo, aqueles que são responsáveis pelas crianças almejam uma certa "respeitabilidade" familiar nas relações escolares, sendo os filhos seus representantes.

Essa posição torna-se compreensível quando verificamos que, em casa, as mães exercem diretamente um "controle" sobre a escolaridade de seus filhos, por exemplo, quando reclamam sobre os "maus comportamentos" na escola, quando verificam se estão realizando as tarefas escolares, quando não permitem que as crianças faltem à escola. E, ainda de forma indireta, diminuindo as saídas à rua, limitando o tempo diante da televisão, levando-os e trazendo-os da escola para casa etc. Na comunidade investigada, os familiares controlam essas situações para evitar que os filhos não desistam dos estudos nem caminhem para "fazer coisas erradas”. Por essa via, Lahire (2005) considera que, "fora dessa ação socializadora, que se concentra no aspecto moral das condutas infantis, o universo do- 
méstico, através da ordem material, afetiva e moral que reina ali a todo instante, pode desempenhar um papel importante na atitude da criança na escola” (p. 25).

Constatamos tal percepção no pouco investimento que as famílias fazem em relação a outros materiais de escrita que não os de influência escolar. Seja pela experiência escolar vivenciada pelos pais, seja pela preocupação com o desempenho escolar dos filhos, a circulação de textos escritos nas redes primárias acontecem pelo uso dos livros didáticos e da literatura infantil.

Embora ainda permaneça a tendência de representar os meios populares como classes homogêneas, constatamos uma diversidade de relações que os meios populares podem ter com os textos escritos. Essa diversidade, que outorgamos a classes sociais favorecidas economicamente e com amplo capital cultural, também é percebida para quem a reconstrói através de pesquisas etnográficas nos meios populares, superando a ideia de "vocacionalismo" das massas.

\section{Considerações finais}

Em nossas sociedades, atravessadas por desigualdades variadas e complexas, existe uma "fronteira” na ordem sociolinguística que consiste nas práticas de uso da língua não incorporadas pelos sujeitos porque não há suficiente "comunicação" com as redes sociais de pertencimento. Existem, portanto, redes densas (e intensas) - como a escola, as famílias, as associações, a comunidade - que permanecem pouco ligadas umas às outras mas interferem no trabalho pedagógico, com práticas de letramento presentes em uma dada configuração social. Permanece ainda o problema de como articular a linguagem das redes sociais concretas das crianças com outras redes sociais: escolares, profissionais, do mundo público. A questão fulcral, portanto, é como ampliar gradualmente os recursos disponíveis nas redes comunitárias locais e conseguir que os recursos sistematizados da linguagem (escrita, música, cinema, software) ultrapassem essa fronteira invisível; como fazer com que as práticas de letramento se estendam a partir do contato, por exemplo, com as regras formais vigentes em outros grupos sociais.
As conclusões da abordagem etnográfica poderão levar a diferentes avaliações daquilo que se pode apreender como letramento "eficaz", a diferentes exigências quanto a resultados e a currículos e a formas pedagógicas distintas dos muitos programas tradicionais promovidos pelos sistemas educacionais.

Em relação às práticas de letramento cotidianas da comunidade e da escola, é preciso que esta ofereça uma estrutura aberta, que torne possível a participação de uma parceria com iniciativas locais que vise à elaboração baseada em práticas já existentes de letramento e de comunicação: o objetivo não é simplesmente aumentar o número de alunos aprovados em testes de alfabetização, mas expandir as práticas comunitárias de letramento.

Nossa compreensão, portanto, é de que fazer uso das práticas de leitura e escrita exige mais do que o domínio de um código; exige um necessário reconhecimento mútuo: falar a linguagem da outra pessoa transcende falar numa língua dada, pressupõe certos usos simbólicos da língua que podem favorecer ou dificultar uma linguagem comum. Acreditamos que os recursos teórico-metodológicos derivados tanto da perspectiva do letramento quanto das redes sociais permitirão ressignificar as táticas concretas para a consolidação, o alargamento e a ligação dos sujeitos (professores e alunos) que compartilham o objetivo de acessar o mundo letrado.

\section{Referências bibliográficas}

BOURDIEU, Pierre. Escritos de educação. Trad. Maria Alice Nogueira \& Catani. Petrópolis: Vozes, 1998.

.; PASSERON, Jean Claude. A reprodução: elementos para uma teoria do sistema de ensino. Trad. Reynaldo Bairão. Rio de Janeiro: Francisco Alves, 1975.

CÁCCAMO, Celso A. Redes sociais na transmissão da língua: o papel dos locais sociais. Buenos Aires: s.ed., 2004. Mimeografado. CHADI, Mónica. Redes sociales em el trabajo social. Buenos Aires: Espacio Editorial, 2000.

DABAS, Eliana. Redes sociales, famílias y escuela. Buenos Aires: Paidós, 2003.

DORNELES, Beatriz. V. Mecanismos seletivos da escola pública: um estudo etnográfico. In: SCOZ, B. J. L.; RUBINSTEIN, E.; 
ROSSA, E. M. M.; BARONE, L. M. C. (Orgs.). Psicopedagogia: o caráter interdisciplinar na formação e atuação profissional. Porto Alegre, 1987. v. 1. p. 251-274.

FREITAS, Alexandre Simão de. Fundamentos para uma sociologia crítica da formação humana - um estudo sobre o papel das redes associacionistas. Tese (Doutorado em Sociologia) - Centro de Filosofia e Ciências Humanas, Universidade Federal de Pernambuco, Recife, 2005.

GEERTZ, Cliford. A interpretação das culturas. Rio de Janeiro: Zahar, 1978.

LAHIRE, Bernard. Sucesso escolar nos meios populares; as razões do improvável. São Paulo: Ática, 2005.

LEWIS, Michael. Alterando o destino. Por que o passado não prediz o futuro. São Paulo: Moderna, 1999.

LOPES, Iveuta. Cenas de letramento sociais. Recife: Programa de Pós-Graduação em Letras da UFPE, 2006.

MARTÍNEZ, Albertina. M. O outro e sua significação para criatividade: implicações educacionais. MARTÍNEZ, A. M.; SIMÃO,

L. M. (Orgs.). O Outro no desenvolvimento humano. São Paulo: Pioneira, Thompson Learning, 2004.

MORTATTI, Maria. Educação e Letramento. São Paulo: UNESP, 2004. RODRIGUES, Joel C.; BOSCO, Sérgio M. (Orgs.). Redescobrindo o adolescente na comunidade. Uma outra visão da periferia. São Paulo: Cortez, 2005.

SACRISTÁN, J. Gimeno. Educar e conviver na altura global: as exigências da cidadania. Trad. Ernani Rosa. Porto Alegre: Artmed, 2000.

SARTI, Cynthia A. A família como espelho: um estudo sobre a moral dos pobres. São Paulo: Cortez, 2003.

SLUZKI, Carlos. A rede social na prática sistêmica: alternativas terapêuticas. Trad. Cláudia Berliner. São Paulo: Casa do Psicólogo, 1997. SOARES, Magda. Letramento: um tema em três gêneros. Belo Horizonte: Autêntica, 1998.

Linguagem e escola: uma perspectiva social. 13. ed. São Paulo: Ática, 1986.

SPOSITO, Marilia Pontes. Uma perspectiva não escolar no estudo sociológico. In: ZAGO, N.; PAIXÃO, L. P. (Orgs.). Sociologia da educação: pesquisa e realidade brasileira. Petrópolis: Vozes, 2007. STREET, Brian V. Literacy in theory and practice. Cambridge: Cambridge University Press, 1984.

TERZI, S. B. A construção da leitura: uma experiência com crianças de meios iletrados. Campinas: Pontes; Ed. da UNICAMP, 1995. WACQUANT, Loic. Os condenados da cidade. Rio de Janeiro: Fase, 2001.
YOUNG, Michael. Para que servem as escolas? Educação e Sociedade, Campinas, v. 28, n. 101, p. 1.287-1.302, set./dez. 2007. Disponível em: <http://www.cedes.unicamp.br>. Acesso em: 22 mar. 2007.

ANA CLÁUDIA RIBEIRO TAVARES, mestre em educação pelo Programa de Pós-Graduação em Educação da Universidade Federal de Pernambuco (UFPE) e doutoranda em educação pela mesma universidade, é membro do Centro de Estudos em Educação e Linguagem (CEEL). Publicações recentes: com BRITO, Andréa T. As redes sociais no cenário educacional: perspectivas teóricas e metodológicas (In: CONFERÊNCIA INTERNACIONAL EDUCAÇÃO, GLOBALIZAÇÃO E CIDADANIA - Novas perspectivas da sociologia da educação. Anais... João Pessoa: s.ed., 2008. 1 CD-ROM); Filosofia e a formação do humano (In: COLÓQUIO FRANCO-BRASILEIRO DE FILOSOFIA DA EDUCAÇÃO - Filosofia, aprendizagem, experiência, 4., Rio de Janeiro, 2008. Anais... Rio de Janeiro: s.ed., 2008. 1 CD-ROM); com ALBUQUERQUE, Eliana B. C.; BRITO, Andréa T.; CABRAL, Ana Catarina. Livros de alfabetização: como as mudanças aparecem (In: REUNIÃO ANUAL DAANPED - ANPED: 30 anos de pesquisa e compromisso social, 30., Caxambu, 2007. Anais... Caxambu: ANPEd, 2007. 1 CD-ROM). Pesquisa em andamento: “Teoria crítica, espiritualidade e formação humana: uma contribuição ao debate sobre as formas de subjetivação na sociedade contemporânea”.E-mail: anatavares07@yahoo.com.br

ANDRÉA T. DE BRITO FERREIRA, doutora em educação pela Universidade Federal de Pernambuco (UFPE), é professora do Programa de Pós-Graduação em Educação da mesma universidade, no qual coordena o Centro de Estudos em Educação e Linguagem (CEEL). Publicações recentes: com ALBUQUERQUE, Eliana Borges Correia de; MORAIS, Artur Gomes de. As práticas cotidianas de alfabetização: o que fazem as professoras? (Revista Brasileira de Educação, v. 13, n. 38, maio/ago. 2008); com ALBUQUERQUE, Eliana Borges Correia de. A construção/fabricação de práticas de alfabetização em turmas de jovens e adultos (Educação, UFSM, v. 33, p. 425-439, 2008); com CHARTIER, A. Brésil - France au quotidien de l'école (Diversité, Montrouge, v. 150, p. 179-189, 2007). Pesquisa em andamento: “A construção/fabricação de práticas de alfabetização em turmas de educação de jovens e adultos”. E-mail: atbrito@superig.com.br

Recebido em outubro de 2008 Aprovado em dezembro de 2008 
escolar é insuficiente. $\mathrm{O}$ analfabetismo absoluto alcança $12 \%$ da população jovem e adulta e $40 \%$ dela têm, no máximo, quatro anos de estudos. Só há centros educativos em $30 \%$ dos assentamentos, reflexo das políticas públicas que privilegiam o transporte escolar para as cidades. Embora as condições materiais de estudo fossem razoáveis, as escolas dispunham de poucos meios para enriquecer o currículo e as práticas pedagógicas, cuja referência dominante é a cultura urbana. Esta política é contestada pelos movimentos sociais, que reivindicam a construção de escolas no campo capazes de desenvolver uma proposta educacional integrada ao universo cultural do campesinato e ao seu projeto político de transformação social.

Palavras-chave: educação e movimentos sociais do campo; assentamentos rurais; educação de jovens e adultos.

Schooling in Rural Settlements in the State of São Paulo: an analysis of the National Research on Education in the Agrarian Reform 2004 (Pesquisa Nacional de Educação na Reforma Agrária 2004)

The study regarding schooling in rural settlements in the State of São Paulo, based on data from the National Research on Education in the Agrarian Reform 2004 (Pesquisa Nacional de Educação na Reforma Agrária 2004), verified that the right to education was only assured to those children who frequented the initial years of primary education; at the other levels and modalities, including youth and adult education, the offer of schooling is insufficient. Absolute illiteracy affects $12 \%$ of the youth and adult population and $40 \%$ among them have, at the most, four years of formal studies. There are educational centres in only $30 \%$ of the settlements, which is a reflex of the public policies that privilege school transport to the cities.
Although the material conditions of study were reasonable, the schools had few resources with which to enrich the curriculum and pedagogical practices, for which the overriding reference is urban culture. This policy is contested by the social movements which demand the construction, in the countryside, of schools that are able to develop an educational proposal integrated with the cultural universe of the peasants and their political project of social transformation.

Key words: education and social movements in the countryside; rural settlements; youth and adult education.

\section{Escolaridad en asentamientos en el Estado de São Paulo: un análisis} la Encuesta de Educación en la

\section{Reforma Agraria 2004}

El estudio sobre la escolaridad en los asentamientos rurales del Estado de São Paulo, con base en los datos de la Encuesta Nacional de Educación en la Reforma Agraria 2004, constató que el derecho a la educación sólo estaba asegurado a los niños que frecuentaban los primeros años de la enseñanza fundamental; en los demás niveles y modalidades, inclusive la educación de jóvenes y adultos, la oferta escolar es suficiente. El analfabetismo absoluto alcanza $12 \%$ de la población joven y adulta y $40 \%$ de ella tiene, en lo máximo, cuatro años de estudios. Sólo hay centros de educación en $30 \%$ de los asentamientos, reflejo de las políticas públicas que privilegian el transporte escolar para las ciudades. Aunque las condiciones materiales de estudio fuesen razonables, las escuelas disponían de pocos medios para enriquecer el currículo y las prácticas pedagógicas, cuya referencia dominante es la cultura urbana. Esta política es contestada por los movimientos sociales, que reivindican la construcción de escuelas en el campo capaces de desarollar una propuesta educacional integrada al universo cultural del campesinado y a su proyecto de transformación social.

Palabras claves: educación y movimientos sociales del campo; asentamientos rurales; educación de jóvenes y adultos.

Ana Cláudia Ribeiro Tavares e

Andréa Tereza Brito Ferreira

Práticas e eventos de letramento em meios populares: uma análise das redes sociais de crianças de uma comunidade da periferia da cidade do Recife

Nos diagnósticos e documentos norteadores das políticas públicas de educação, as crianças provenientes de comunidades de baixo poder aquisitivo são comumente associadas à ideia de fracasso escolar. Acreditando que a discussão sobre o letramento só faz sentido se for abordada a partir de condições que tornem possível sua compreensão contextual e não como mais um "modismo educativo", esta pesquisa investigou as práticas e eventos de letramento em uma comunidade da cidade do Recife a partir dos momentos de interação das crianças com a escrita, pela ótica de suas redes sociais de pertencimento. A perspectiva metodológica se caracterizou pela aplicação do mapa de redes com as crianças, entrevista e observações. O reconhecimento das práticas de letramento constitui redefinições nas situações de interação, pois, à medida que as crianças passam a confiar no "outro", constroem um fator de valoração que as leva a considerar que é significativo participar dos eventos em que a leitura e a escrita são cruciais para fazer sentido em suas relações sociais.

Palavras-chave: redes sociais; letramento; meios populares.

Practices and events of literacy in popular environments: an analysis 
of children's social networks in a community on the outskirts of the city of Recife

In the diagnoses and guiding documents on public policies in education, children coming from lowincome communities are commonly associated with the idea of school failure. Believing that the discussion on literacy only makes sense if it is approached taking as its starting point conditions that make possible their contextual understanding and not as yet another "educative vogue", this research investigated the practices and events of literacy in a community in the city of Recife based on moments of interaction of children with the written word, from the perspective of the social networks to which they belong. The methodological approach was characterised by the application of the map of networks with children, interviews and observations. The recognition of literacy practices constitute redefinitions in situations of interaction, because, as the children begin to trust in the "other", they build a valuation factor which leads them to consider that it is meaningful to take part in events in which reading and writing are crucial for making sense of their social relations.

Key words: social networks; literacy; popular environments.

Prácticas y eventos de letramento en medios populares; un análisis de las redes sociales de niños de una comunidad de la periferia de la ciudad de Recife

En los diagnósticos y documentos orientadores de las políticas públicas de educación, los niños provenientes de comunidades de bajo poder adquisitivo es común asociarlos a la idea de fracaso escolar. Creyendo que la discusión sobre el letramento sólo tiene sentido si fuera abordada a partir de condiciones que hagan posible su comprensión contextual y no como más un "modismo educativo", esta pesquisa investigó las prácticas y eventos de letramento en una comunidad de la ciudad de Recife a partir de los momentos de interacción de los niños con la escrita, bajo la óptica de sus redes sociales de origen común. La perspectiva metodológica se caracterizó por la aplicación del mapa de redes con los niños, entrevistas y observaciones. El reconocimiento de las prácticas de letramento constituye redefiniciones en las situaciones de interacción, pues, a medida que los niños pasan a confiar en el "otro", construyen un factor de valorización que los lleva a considerar que es significativo participar de los eventos en que la lectura y la escrita son cruciales para hacer sentido en sus relaciones sociales.

Palabras claves: redes sociales; letramento; medios populares.

Filomena Maria Gonçalves da Silva Cordeiro Moita e

Fernando Cézar Bezerra de Andrade

Ensino-pesquisa-extensão: um exercício de indissociabilidade na pós-graduação

Discute-se a indissociabilidade ensinopesquisa-extensão como princípio orientador da qualidade da produção universitária. Embora se reconheça a importância de articulações duais (entre ensino e pesquisa, pesquisa e extensão ou extensão e ensino), defende-se um princípio que impede reducionismos verificados nas atividades universitárias. Guiados por essa compreensão, durante o estágio de docência, os autores realizaram um exercício da indissociabilidade, que consistiu numa experiência visando a relacionar o conhecimento científico e o saber de educadores e educandos de uma escola pública em João Pessoa (PB), a fim de produzir conhecimento acerca da articulação entre relações de gênero, violência e jogos eletrônicos. Defendese que a indissociabilidade entre ensino, pesquisa e extensão ainda não é levada em conta na prática de muitos docentes, seja porque na graduação dá-se ênfase ao ensino, seja porque na pós-graduação a ênfase incide na pesquisa. Argumenta-se, ainda, que o estágio de docência na pós-graduação é uma excelente oportunidade de praticar a indissociabilidade defendida.

Palavras-chave: indissociabilidade entre ensino, pesquisa e extensão; pósgraduação; estágio de docência.

Teaching, researching and extension: an experience of linking in the Brazilian post-graduation

It is argued that the connection between the activities of teaching, researching and extension as a guiding principle to the quality of the superior education. Although we consider the important links that can be established between only two of those activities, we argue that the articulation of those three activities prevents isolated practices verified in superior education. Guided by that principle, as post-graduation students, we accomplished an intervention in a public local school in João Pessoa $(P B)$. That intervention is presented in this text as an experience that aimed to link scientific discoveries and the educators' and students' understanding about the articulation of gender relationships, violence and electronic games in school. Two central ideas are supported: first, the connection between teaching, research and extension is not still taken into account in practice of many professors in universities, either because in the graduation the emphasis is on teaching, or because in post graduation the emphasis is on research. Secondly, post graduation is an excellent occasion to practice the connection between the three academic activities. 